\title{
Innovations
}

\section{Psychiatric services for remanded mentally disordered offenders: The Brixton Diversion Project}

\author{
Kamaldeep Bhui, Research Associate, UMDS (Guy's campus) \& Health Care Centre, \\ HMP Brixton, Jebb Avenue, Brixton, London SW2; PhILlIP BROWN, Research \\ Fellow, UMDS (Guy's campus) \& Health Care Centre HMP Brixton; Ros \\ SAvouRnin, Research Assistant UMDS (Guy's campus) \& Health Care Centre, HMP \\ Brixton; and JANET ParRotT, Consultant Forensic Psychiatrist, Bracton Clinic, \\ Bexley Hospital, Bexley, Kent DA5 2BW
}

There is growing concern about the care received by mentally disordered offenders (MDOs). The prevalence of psychiatric disorder among the remanded group has received considerable attention (Coid, 1988). Some MDOs are remanded in custody following even petty offences on account of their vulnerability or because their homelessness prejudices bail. Where the offence is serious a remand in custody may be inevitable.

The Department of Health circular $66 / 90$ sought to promote diversion and discontinuance mechanisms as a means of ensuring that offenders do not get caught up needlessly in the criminal justice system. However effectively such schemes operate, there will still be prisoners who develop signs of mental illness and have continuing mental health care needs (Reed, 1992).

The Reed report strongly supported the decision to contract to prisons a full mental health care service. Prison-based psychiatrists have been advocated as one approach to improve care and earlier diversion; greater inter-agency cooperation is seen to be an essential prerequisite to the development of a comprehensive and effective community based service for this client group (NACRO, 1993). The assessment of need as a joint inter-agency activity has been encouraged for difficult to place and offending patients: "this process should enhance a planned coordinated service between health, social services and criminal justice agencies" (Jones \& Dean, 1992).

The Reed report emphasises that the care programme guidelines (Health Circular (90)/23) should be revised to make it clear that the arrangements include discharged prisoners with continuing mental health care needs. Thus prison psychiatric services or psychiatric liaison should be seen as part of the broader network of services likely to be required by this group. This paper describes the structure of a new service based at HMP Brixton; this Department of Health funded research evaluates the impact of having psychiatrists in prison, so as to minimise delays in obtaining second opinions, and examines the process of implementing systematic needs assessments from which care programmes for MDOs may be constructed.

\section{Description}

HMP Brixton was, until recently, the largest remand prison in Europe. The recent closure of ' $F$ ' wing, a 239-bedded wing, has been well publicised. The health care centre now has three 15-bedded wards and a 9-bedded acute unit. Other London prisons now also receive remand prisoners, so reducing the numbers remanded to Brixton. The Project team consists of two post-membership psychiatrists and a psychologist. All new psychiatric receptions remanded to the hospital wing are identified; this effectively includes those on 'mental observations', those remanded for reports concerned with 'the state of mind and health' and those suspected or with evidence of drug addiction.

Prisoners with stable addresses in the South East Thames area and a sample of the homeless are included within the experimental group. A one in two sample from the other health regions forms the comparison group. Both groups are interviewed to obtain baseline socio-demographic information, offence characteristics, forensic and psychiatric histories; rating scales are used to assess neurotic symptoms, cognitive impairment and substance misuse. A brief clinical interview informs the assignation of an ICD10 diagnosis and a DSM-III-R rating of 'global assessment of functioning' is made.

The team discusses each case and completes a needs assessment schedule. This problem orientated assessment includes an evaluation of symptoms and behaviour (including psychiatric symptoms and drug 
and alcohol related behavioural abnormalities), educational, social and personal skills and social situation. The profile of unmet needs obtained in this way informs the construction of a care programme. A series of interventions is selected on the basis of the needs assessment. The agencies likely to deliver these interventions are then contacted and following liaison a discharge plan is formulated.

The prisoner is kept informed of all arrangements so that should he be unexpectedly released before a review, he still has the necessary information to hand and may contact us at the prison. For those prisoners who are remanded for more than a couple of days we invite representatives of any community agencies to meet us, or at least discuss the patients with us at length; the similarity with section 117 meetings is not unintentional but few of the agencies are able to respond to requests for attendance at short notice. Discussion with the prison probation service and the prison NACRO representatives is invaluable in further ensuring co-ordination of services and exploring alternative community resources with which we may not be familiar. We are evaluating the effectiveness of our interventions by examining the extent to which the recommendations of our needs assessments and care programmes are fulfilled. Service uptake or loss of contact with services will be documented and factors responsible for shortfalls within existing service structures will be identified.

\section{Problems}

A major hurdle in securing a greater level of involvement by community agencies is that the fate of any one prisoner is not known until he has attended court. Understandably, preparation in anticipation of release or bail may be perceived as a waste of resources if the prisoner is remanded again or sentenced. One might be persuaded that this is more likely in those with less serious offences or in those without major mental illness, as in these cases one can predict with less certainty the likely outcome of court appearance. Indeed NACRO (1993) suggested that it is these groups who repeatedly re-offend and also do not receive adequate health and social care as they are never seen as a high priority and are more likely therefore to 'fall out of care'.

The GP is of pivotal significance in gaining access to health and social care. We attempt to secure a GP for many prisoners who do not have one; however, drug-related behaviour or violence may have been significant factors in the failure of service provision or uptake in the past. Arranging for a GP to coordinate services for an individual in anticipation of release is then especially difficult. At release a brief summary of our contact with the patient is sent to the GP. If insufficient time precludes securing a GP, we encourage the prisoner to register on release and contact us with the details.

Of those remanded, the homeless MDOs present particular challenges to established services. It is often unclear which catchment area psychiatrist should take responsibility for homeless people. If an MDO is of 'no fixed abode' then the site of the offence determines which district health authority and hence catchment area consultant takes responsibility for the provision of aftercare. There is often insufficient time to plan this too far in advance as a prisoner may be returned to court within days, released and hence lose contact. A GP in this instance may be more quickly arranged so that some aftercare is available while local psychiatric boundary or responsibility disputes are resolved. This raises the question of how to provide health and social care for those with no stable address or GP and for those without any benefits.

\section{Comments}

The Royal College of Psychiatrists published guidelines for the aftercare of potentially violent or vulnerable patients discharged from in-patient psychiatric treatment (Royal College of Psychiatrists, 1991). This emphasised the multidisciplinary nature of such work and encouraged formal discharge planning meetings. The Reed report suggests that similar procedures should be invoked in the case of MDOs. The Brixton diversion project seeks then to put into practice and evaluate discharge planning for MDOs. This is a formidable task as not only does it involve changing attitudes towards MDOs in prisons and the community, but it also seeks to form channels of communication and harmonise the efforts of fragmented community services.

\section{References}

CorD, J. (1988) Mentally abnormal prisoners on remand: rejected or accepted by the NHS? British Medical Journal, 296, 1779-1782.

Jones, D. \& DEAN, M. (1992) Assessment of need for services for mentally disordered offenders and patients with similar needs. Health Trends, 24, 48.

NACRO (1993) Community Care and Mentally Disturbed Offenders. Policy Paper 1. London: National Association for the Care and Resettlement of Offenders.

REED, J. (1992) Review of the Health and Social Services for Mentally Disordered Offenders and others requiring similar services. Final Summary Report. London: HMSO.

Royal College of Psychiatrists (1991) Good Medical Practice in the Aftercare of Potentially Violent or Vulnerable Patients discharged from Inpatient Psychiatric Treatment.

A full list of references is available on request to the authors. 